\title{
The Factors Affecting Villagers' Participation in a Sustainable Forest Management in Champasack Province, Lao PDR
}

\author{
Bounyadeth Thongsavanh ${ }^{1}$, Khanthaly Khamphilavong ${ }^{1}$, Sovu ${ }^{1}$
}

\author{
${ }^{1}$ Faculty of Forest Science, National University of Lao PDR (NUOL), P.O.Box: 7322, Vientiane, Lao PDR
}

\begin{abstract}
The main purpose of this paper is to determine factors influencing local people's participation in a sustainable forest management in Pathoumphone Production Forest area in Champasak province, Lao PDR. In order to assess these factors, we had chosen 12 target group representatives: household representatives, village authorities, international aid agencies, central and local government agencies (Champasak Provincial Office for Agriculture and Forestry Office and District Office for Agriculture and Forestry Office). Household and village representatives are from Beuangko village, NamOm village, Nongbeuang village, Chongroy villages, and Phaosamphan village. Purposive Sampling was used to achieved the aim of this study. The analysis found that the factors that influenced villagers to participate in the sustainable forest product management consists of three main factors: economic factor, social factor, and other external factors with related to the project's activities on the forest product management while providing knowledge to local people was also important. Policies should be reformed in order to strengthen village committees and they can be self-managed and benefits-sharing mechanism should be established in order to improve the participation of local villagers in the Production forest management.
\end{abstract}

Keywords: Participation, People, Production Forest, Champasak, Lao PDR

\begin{abstract}
I. Introduction
Since Laos has been declared their independence, the government of Laos (GoL) focused on forestry as one of the vital priorities to periodical contribution on national development (DOF, 2007). Initially, GoL spent their incomes from selling timber to expand agriculture area and extension activities for improving livelihood. Forest management was initially only managed by GoL until 1986, and due to global social economics changes, the GoL began to review existing policies and revised new policies on economics from selve-support procedure to be producing for trading. In particular, the policy of forestry had allowed private sectors to be involving with the management, protection, development and utilization. This was a first step forward for forestry participation in Laos (MAF, 2011).
\end{abstract}

In 1989, the first National Forestry Meeting has been held for assessing implementation of forestry policies because the forest area in Laos had been destoryed and decreased nationwide. In opposition, the income was from natural resources which did not hand over to the national exchequer as determined. Therefore, the policy required its new revision to increase and obtain the national forest area at $70 \%$ in 2020 and proposed the areas for havresting logs under the management plan to avoid complicated harvesting. In
1993, some eighteen National Biodiversity and Conservation Areas (NBCAs) or National Protected Areas were established by the issue of the Prime Minister's Decree No. 164 (Berkmüller et al., 1995; Robichaud et al., 2001; Sanonty, 2002).

Currently, forest in Laos has been classifying into 3 catecgories such as protection forest, conservation area and production forest. The National protection had a total area of $8,045,169$ ha (49 areas), conservation area 4,705,809 ha (that included the 24 national parks, 66 provincial conservation areas and 143 district conservation areas). The production area had the total area of 3,203,623 ha, this included 51 areas nationwide.

The GoL has set a developing goal on sustainable management project based on the extension and supports of rural participation on project planning, involving with identifying and implementing project's activities, monitoring and verification on the project implementation and the benefits gained from their participated to the project to achieve project's goal in improving livelihood for sustainable manner under the creation of livelihood development fund that focused on integrated agriculture and forestry and also contributed to the forest management and

This article is published under the terms of the Creative Commons Attribution License 4.0

Author(s) retain the copyright of this article. Publication rights with Alkhaer Publications.

Published at: http://www.ijsciences.com/pub/issue/2019-08/

DOI: 10.18483/ijSci.2155; Online ISSN: 2305-3925; Print ISSN: 2410-4477 
The Factors Affecting Villagers' Participation in a Sustainable Forest Management in Champasack Province, Lao PDR

sustainable natural resources management(DOF, 2005).

An attempt to achieve the goal, in 1996, the GoL initiated a pilot project in Dongkapor Production Forest in Nathong village, Phin district, Savannakhet province. Forest inventory and harvesting management plan have been done with a collaboration among government officers and villagers and together with the contract selling with wood industry sectors. According to the principle that $\mathrm{GoL}$ is responsible for implementing the regulations but the profits are belong to villagers since the failing tree, cutting into billets, dragging and transporting $\operatorname{logs}$ to $\log s$ yard II were done by villagers. The income will be saved in the village development fund account for village services for village development fund based on the village committee's discussion and agreed on each activity that required funding. This is an initial effort for participatory in forest management in Laos. However, the results are still not be able to apply for other villages due to different factors and other conditions involved ${ }^{(1)}$ which is to result was unsuccessful.

As implemented in investigating a suitable model for participatory forest product managment as a pilot project which was conducted in Dong Kapor was not successful. However, the GoL continued implementing a new project called Forest Management and Conservations Project (FORMACOP) for 1996-2005, the project has been collaborated with three partners (Lao PDR, Finland and Worldbank-Global Environmental Fund) implemented in 2 forest products of two provinces, i.e. Savannakhet province (DongSithouan) and Khammouan province (DongPhousoi). The project's aims were to provide trainings of trainers on capacity building for provincial and district offcials, after that they can conduct trainings for villagers who is implementing activities in the field based on an organized forest association or known as village forest unit where aprooved by the GoL based on the provincial logging quotas. In adition, the purchassing timber must go through the the legal bidding processes. The logging processes were conducted by village forest unit together with provincial logging authority then transporting logs to the log yard II for listing details that is conducted by forest section together with trading section, after that the bidding winer will continue other processes after all related payment has been done. The income will be sharing, GoL will receive fee of selling timber based on price that has been determined by the Ministry of Industry and Commerce, the rest of portion is considered as profit but maintenance costs must be deducted before handing the income to the village forest unit. Although the implementation of this project has considered its successful for a larger scale but there are still having several issues that need to be addressed ${ }^{(2)}$ so that the GoL is continueing in seeking for a suitable model for forest product manageent (World Bank et al.,
2001).

In 2003, under the supports of International Organizations and International Financial Institutions, especially, WorldBank to support on Sustianable Forest for Rural Development-SUFORD. The pilot project have been conducted in 4 provinces in the Southern part of Laos (Khammouan, Savannakhet, Salavan and Champasak for the first phase of 2003-2008 and the second phase was scaled up to other 5 provinces included Borikhamxay, Vientiane, Xayabury, Attapue and Sekong (Sustianable Forest for Rural Development Project Additional Financing-SUFORD AF) (World Bank et al., 2001).

Since 2014, the third era has been implemented and the project was ended in 2018. In addition, the project has determined three areas in Northern provinces such as Borkeo, Louang Namtha and Oudomxay province that needs to be focused on (Sustianable Forest for Rural Development Project Scaling UpSUFORD SU) to archeive the goal of participatory implementating activities to reducing deforestation and forest degradation (Reducing Emissions from Deforestation and Forest Degradation and the Role of Conservation, Sustianable Management of Forest and Enhancement of Forest Carbon stocks in Developing Countries-REDD+) the activities of sustainable forest governance based on community participation that was implemented in only the prioritied area of 4 provinces (DOF, 2015).

Realistically, the project that implemented in Champasak province, the province has permitted to loggings for $700 \mathrm{~m}^{3}$ in two production forests, i.e. Pathoumthone production forest for $200 \mathrm{~m}^{3}$ and Silivangvern production forest for $500 \mathrm{~m}^{3}$. There were 25 timber species have been harvested. Although having a clear planning and management there still had some negative impacts and challenges on related management areas of villagers that required the utilization of natural forest for livelihood (Timber utilization, NTFP and areas for agriculture) and illegal logging practice for selling due to a good price of logs that offered by a middle man. Thus, this was a main problem that identified that villagers who were living in the production forest had no involve in the sustainable forest product management but it had direct impact on natural forest products in the area has decreased, i.e. forest, forest area and NTFP. The resolution was only based on academic and regulations for utilization and protection but there was not fully successful yet. In addition, there was lack of the study on timber markets, communication among relevant stakeholders were reluctant and had yet fulfill their jobs descriptions, this caused uncomfortable in forest management and planning, missing of involvement of villagers, lack of intention 
from the central level to locals. However, at that time the points of discussion could not solve the problem immediately.

As the issues stated above, the villager participation has been initiated due to existing policies and procedures sometimes were not fit to the real circumstances of locals and sometimes might not fulfill the needs of the villagers or other cases, the implementation of the state sections, project, private and villagers are lacked of understanding on the implementing the determined regulations. Importantly, if the villagers have no benefit sharing from their participation in the forest management, although offering some budgets (8000 USD/villager) from the support of projects, however, the budget was not used in a proper way, this could affect to the intention on implementation of participatory sustainable forest management. If that was true, without seeking the resolution based on academic procedure to determine strategy and policies for forest management in the future it would be just a theory that was not suitable to the forest product in Champasack province. Thus, forest management has considered as a vital part in utilization and protection for the participatory benefits sharing among state sections and local residence in a sustainable manner.

There have been few researches examining factors influencing people's participation in the participatory forest management program. Therefore, this paper was conducted with the aim of identifying and characterizing factors that influence local people's decisions to participate in the forest management program and ways through which the Forestry authories affect local people's participation in the program in Champasak province. For this analysis, participation in forest management refers to any participants in forest management activities, decision-making and benefiting from forest management activities.

\section{Method}

This study employs a qualitative research study that focuses on diversity and seeks to understand the perspectives of people in the community and those involved in sustainable forest management in Champasak province. The study was divided into two stages: a documentary research and data collection on a field-based, multi-method and multi-stage study based on the research questions identified by the process (Yin, 2009).

In order to assess the factors that motivate the people living in the Production forest area supported by SUFORD to participating in managing sustainable production forests in Champasak province, we had selected 12 target group representatives: household representative, Village Authorities, International Aid
Agencies, Central and Local Government Agencies (Champasak Provincial Office for Agriculture and Forestry Office and District Office for Agriculture and Forestry Office). Household and village representatives are from Beuangko village, NamOm village, Nongbeuang Village, Chongroy Villay, and Phaosamphan Village. Purposive Sampling was used to achieved the aim of this study.

The main research tool is a semi-structured questionnaire form developed under the supervision of the supervisors at the National University of Laos.

We submited a draft assessment that motivates the people to participate in Sustainable Production Forest Management (SUFORD) in Champasak province, subject to the approval of the Research Advisory Committee for Content Validity.

In order to check the quality of the questionnaire form by asking three experts to check the accuracy of the content (Content Validity), then calculate index of item congruence: IOC. Selecting question valuable consistency 0.50 to that question is the nature of the query as a percentage value 3 level: consistent (3), inconsistent (2) and uncertain (1). Experts are persions to consider consistency of the quality of the instrument.

The researchers requested a letter from the Faculty for Forest Science in order to approach target groups for an in-depth interview on the factors that motivate people to take part in sustainable forest management (SUFORD) in Champasak province. The researcher collected the data in several times in Champasak Province.

For data processing and analysis, data from interview and questionnaire form are coded, sorted, categorized, and then analyze the content.

From an analysis of community involvement guidelines for sustainable forest management in Champasack Province. The researcher uses the Mixed - methods of Qualitative Research and Quantity Research to conduct the research in three stages.

\section{Result}

The factors that influenced villagers to participate in the sustianable forest product management in Pathoumphone, Champasack province are explained as follows:

\subsection{An economical factor}

Villagers that participated must receive benefits with satisfaction which would lead villagers to prosperous and wealthy from the implementation of forest product management. 
Promote villagers to grow industrial plants and they must taking care of their plants to be able to supply and selling, this would allow villagers to collaborate with the government or forest product management project.

Promote permanent job for villagers such as farming of duct, chicken, pigs, goat, cao, buffalo and others based on the conditions of the villages or sub areas then seeking for the market for them, this activities would stop them to destroy the forest.

Promote villagers to create forest product area to become an ecotourism and tradition of the village, this would create source of income for the village (Especially, Nong Boueng village, Phaphue village....)

Reforestation the degraded forest to become a forest again by competition among differnt areas. This was to awareness of natural resource conservation of the village. Promoting villagers to pay attention on forest product protection, investigate, participatory maintenance and get fine those infringement.

\subsection{A social factor}

Assist people to get well education, have access to foods, have clothes, sleep tight and wealthy. People could get access to hospital and the medicines are available for releasing illness. It helps a better quality of life. If local people have jobs, enough income they won't enter to the forest for illegal logggings because they already had income from other sources. Local people could get access to the governmental agencies and private sectors. When they had good economics that can support their needs, they would not interfere to the forest and their lives would be more prosperous.

\subsection{Project participation and activities factors}

Local people percived the project's activities on the forest product management, being a reprent of the local people or government that has been proposing and recieving information, participating with project and involing with activities of forest product management. Hence, local people has the right for benefit sharing as individual or community so that they would collaborate with the project implementation. The project selected ones who had experiences as well as had a role in the village committees so that they could maintain continuation of recieving the benefits. The willingness of local participation on the project activities would stimulate themseves to contribute their responsibility in forest product management. Participated by local people derived from organizing meetings with clarifying to village committees, head of the villager informed that they are willing to involve with sustainable forest management.

\subsection{Archievements of local participatory in forest product management.}

1.) Offering perceivability to local people.

Before starting the project, perceiving and unsterstanding of the villagers are the most important to inform the benefits and positive impacts to the villagers to motivate their participation. The project officials must be clearly dertermined and understood their responsibilities. Training, demonstration, seminars are also neccesary for local people due to their perceivility and perspectives are the keys of project's implementation in the village. Training and implementing project's activities should be continuously conducted to make sure that local people were interested and better understanding. Providing knowledge to local people was a task to reduce problems of leadership in the village. Creating manual for planning and regulations together with local people and used it correctly and disseminating to their children.

\section{2.) Giving rights to local people in forest product management.}

Local people's praticipation should be initiated with giving the transparency information and operational plan, after that giving the right to local people to express their opinions on the project's activities included decision making on each methods. Allowing local people to think and making decision by assuming that he/she is responsible for some activities, this is to let them deeper understanding the value of themseves so this would help them to be brave in providing suggestions on any activity. Local people must be a knowledgable persons who can lead the tasks this will help them to be more stronger on any aspects. Giving rights to local participation is important under the training on providing knowledge with continuous training to make sure their competency and get used to with involving with project's activities. Local people must involve with siteseeing and their involvement with decision making in forest product management.

\section{3.) Distribution of powers and responsibilities in} caring forest product management groups.

The use of power and distribution of participation and accountability will bring a sense of pride in the expression of ownership and belonging of the people or villagers to the people who have been responsible and cared for, a difficult bond to care for themselves. Offering the benefits that the people or people will get from being assigned or responsible in the production areas will make people appreciate and value what they will get from such activities. Most villagers are involved in a manner that is neglected in their own role, with the public agency at each level monitoring, inspecting, managing their own fields in 
the fields of production forest at every stage. The demarcation of production forests in the area of a village or village group as a community forest by all the villagers has the right to take advantage of some of the benefits of the forest and provide protection management to help sustain the forest. The people or villagers have the role and role to play in meeting the needs of the people in each regard and to bring the requirements to the relevant agencies so that they can be tailored, allocated and planned to suit the needs of the people and accurately and effectively benefit the villagers.

People or villagers lack the conceptual understanding and importance of public participation. The rules and policies for production forest management also do not facilitate adequate participation in guiding people to truly participate. The lack of personnel or officials who are capable of using the tools of public participation also causes problems for the people, and lacks people with a clear understanding of the people. Cultural traditions and hegemony are also involved in public participation, as some of the people they adhere to may make certain projects or activities he or she considers important. People still have to come to work and raise a family to attend a program or event, most people or villagers find it helpful to attend. Many state-owned projects or programs bring in people or people operating on the project's needs or activities, not by the needs of the people or by the people who want to benefit the people and not cooperate. State-level readiness in practice is important since the feasibility study of the project, the materials, personnel and other relevant factors must be ready to ensure that the project is fully implemented. People or villagers are reluctant to comment on the project and the state for fear of illegally joining the project or the government as needed. Village management and village tract committees are weak and lack formal, informal approaches.

\subsection{Factors and problems of sustainable forest management in the implementation}

The study has found that

1. Strong interpersonal and leadership skills with an honest vision, sacrifice and good coordination both internally and externally are the key success.

2. Powerful village organizations need to have confidence in their development and people have a good deal of internal and external cooperation.

3. Learning Management, there is a process of collaborative learning within the group and between organizations with ongoing or monthly meetings to resolve issues promptly.
4. Villagers are involved in the decision-making and the purpose of the action is to clearly identify the stakeholders who have clearly benefited from the legitimate benefits and actions that have been taken by the villagers themselves.

5. The right to take advantage of natural resources defines a clear scale and geographical area, defines the capacities of villagers' support, and engages them in four areas:

\section{1.) In terms of participatory planning, incentives should be encouraged by government:}

Award certificate to people or communities involved regularly as to people right - that is, the benefit of participation should be meeting monthly to plan the analysis plan to preserve the forest management, production and development of people to network inside - outside village set plan development activities are appropriate and accurate budget. A statement from the government as vocational training, livestock promotion, nursery rhinoceros, forestry and wildlife conservation awareness are vital, and the private sector will always be supportive of the operation to be completely and sustainably with the villagers forever.

\section{2.) The activity should be open to greater participation}

To preserve resources and natural environment such as to preserve water resources, reforestation, protection of forests and wildlife and promote tourism in the village as a measure to solve the problem and management of sustainable to reject the knowledge to preserve sustainable officials and all the people in addition to training professional, education, other participants with the private sector to understand the same, cooperate with public agencies for development and conservation; share ideas on how villagers should use local or local natural resources for commercial or household use in support of the villagers' economy as their income, The staterun agency supports the use of local resources and the promotion of tourism wisdom in order to explore the culture of the villagers, attracting tourists to promote the popular village goods and the allocation of village funds to support tourism operators.

\section{3.) Benefits}

Village committees should be strengthened, selfmanaged and also distributed in a fair manner throughout the region, organizing activities to share knowledge, support people to participate in village activities for their local economy and local pride.

\section{4.) Evaluation}

More people in the village should be monitored, evaluated in all village-related activities, especially in forestry management, to know what the positive and 
negative impacts are, and how they affect the villagers, including the way of life, the local culture, and the village-level control of villages. Analyzing the issue, reviewing the various conservation issues in the public sector, People and other related stakeholders.

So, participation of people in development process play a key role in successful sustainably forest manageme3nt since it gives opportunities for the public and other government like a business, private people and organizations the opportunity to participate in decisions for the development of effective and sustainable social democracy from development related parties of our decision cooperation in operation, exposed Public benefit from the development, the participation of people with access to key elements are: Level information (to inform) News-level counselor (to consult) levels involved (to involve) the level of cooperation (to collaborate) level authority from the decision (to empower) and finally make the quality of life in terms of economic, social, environmental and people see value in the management of production forests to forest increased, aquatic wildlife, increased public preserve water resources, increase food source environment was good, increase the better of life of people, social security, local development strong villagers job activity, forest management produced villagers joined up, making collaboration between government and the people together forest management sustainable of things mentioned above will lead enjoy the quality of life and the sustainability of the villagers.

\section{Discussion}

By analyzing he factors influencing the successful management of production forests sustainably by obtaining the involvement of people in the province of Champasak, it is found that the government lack of the specialist resources to continuously involve with activities between the foreigner's project and governments, as well as lack of communication and public relations across the planning and feasibility study, lack of monitoring and verification on projects / activities (Coulibaly-Lingani et al., 2011) and this is similar to this study. Public participation in production forest management is still lacking especially lack of awareness of the concept and the importance of public participation, as many of the legal structures and policy processes still do not adequately require the involvement of local people. Personnel or officers are lacking the skills the ability to use tools built on the participation of the people because the policy of the announced the Ministry of Agriculture - Forest use resources natural forest purposes, the use of resources forest to develop the welfare of people and a source of capital of the Country after the run to the forest resources. In 1986 the GoL issued Order No. 74 / PM on Conservation of Forests. In 1989 issued the Decree of the Government of Parliament No. 117 / NA on the Management and Use of Forests and Forests in Production Forests through Precise and Precise Surveys by the Public sector and General Recommendations on the Impact of Forestry on Forestry and Forest Service Organizations: Conservation and restoration, improvement and use of biological energy. The most effective use of forests and forest benefits, especially in improving the economic benefits of natural resources and restoring the protection of forest expansion as well as addressing needs (Forest Strategy, 2005, p. 3). 1991 Prime Minister issued Order No. 67 / PM on the cessation of nationwide logging (logging) and abolition of the State Forestry Enterprise for sellingbuying timber Agreement and the Ministry of Agriculture and Forestry issued measures for forest management, harvesting, timber conversion (forestry strategy), and forestry trade (2005, p. 5) and in 19992008 the government ordered on forest concession areas and businesses forests yearly. All provinces being assigned to prepare planting plans and harvesting plan based on the GoL's 4 goals 13 measures of the Ministry of Agriculture and Forestry and the protection plan of forest for development and forest resources management according to system type 3 of forest. National Park, National Protected Forest and National Production Forest. And to increase land covered by forest to $70 \%$ by 2020 .

What benefits do the people, communities, or communities play in the community or village cluster? And make you available to run an agribusiness management program that promotes people or communities for economic growth, and they must own the people or the community so that they can co-operate with the public or the public to provide permanent employment to the people or community

Social factors make people more educated, because people have the money to spend, people can get medicine, they can buy medicine for themselves, the quality of life of the people is getting better so they would not commit with any illegal behavior if the people or the community would not enter to the forest due to community is capable to buy things.

Participation Factors and People or Communities Knowledge on forest protection and Activities Represented by the public or the government and informants who have been involved in the project and the activities of the community forestry have benefited both the whole and the whole community so as to participate in the projects and activities of the production forest, the project or activities will select those who have experience and role in the community to participate in the activities of the 
people involved in the forest management.

1) Providing knowledge, understanding to the public, prior to the initiation of the project, the benefits should be informed to the people and community first. If they want to get involved in a specific project or activity, the responsible person or entity should be actively involved in the training, demonstrations, seminars are essential for people or communities.

2) Providing opportunities for people to manage production forest, segregation between public and private sectors, so that all parties can fully mobilize their own ideas and the plan for transparency forest management should be open to the public to comment on the project or its activities and,

3) Distribution of power and responsibility for forestry management, production, distribution of power, and distribution of responsibility will bring about a sense of ownership and ownership of the people or community that will come to the people responsible and commitment to follow up on the amendment will continue to present the benefits that people or communities will receive from being assigned or responsible in the production areas will make the people or community value and benefited from such actions

\section{Conclusion}

The main purpose of this paper is to identify contextual factors influencing local people's participation in the sustainable forest management in Champasack province, Lao PDR. The analysis has revealed that in terms of public participatory planning, public sector incentives should be incentivized, such as the issuance of certificates to the public or the community as a whole so that the public to realize their rights and duties benefiting from participation. Monthly meetings should be held to identify plans, analyze forestry planning issues and forest management. It is important for people to establish networks within and outside the community; to plan and evaluate appropriate and budgetary activities. The public funding should be used for vocational training, animal husbandry and horticulture, sustainable forestry and wildlife education, as well as community participation to achieve maximum success and sustainability in the community.

The analysis found that the factors that influenced villagers to participate in the sustainable forest product management consists of three main factors: economic factor, social factor, and other external factors with related to the project's activities on the forest product management while providing knowledge to local people was also important. Policies should be reformed in order to strengthen village committees and they can be self-managed and benefits-sharing mechanism should be established in order to improve the participation of local villagers in the Production forest management.

In terms of activities, there should be greater opportunities for greater participation in natural and environmental resources such as water conservation, forest restoration, forest protection and community tourism promotion. Sustainable problem management and management provides knowledge on sustainable conservation to public officials and the community. In addition, to provide vocational training and other education as well as engaging people in the community, the private sector will be directly empowered to cooperate with public agencies in the development and maintenance. Commenting on the use of community benefits should use local natural resources or local wisdom for commercial or household use in support of the community's economy and distribution to the community by relevant public agencies, the use of local resources should be supported and promote local wisdom to explore the culture of the ancestors and to attract tourists to promote the popular village goods and village fund organizations should be established to support community-based and community-based entrepreneurs.

The benefit to the organization committee of the village should be strengthening to capable on managing themselves and distribute income fairly across all parts. Provide training such as the activities of knowledge sharing and support to people in the community involved in the activities of community economic growth and local gathering and natural resource conservation encourages people in the community to earn more from the profession.

In terms of evaluation, the community should be more involved in monitoring and evaluation of all community-related activities, especially the management of production forests, in order to identify the positive and negative impacts of the project on one side, impacting the community on the way of life and the local culture and Analyzing the issues and reviewing the obstacles, and jointly pursuing a holistic approach to development of both the private, the local residence and the public and the stakeholders, as the researchers conducted the study from relevant data, interviewed government officials, the public and other stakeholders.

The concept of change must be changed if the people are to understand it properly. Officials should trust three points: believing that people living in or near the forest are aware of the value of forests to humanity. It is believed that people living in or near the forest have an understanding of the proper tree planting techniques. It is believed that such people will protect the trees and manage the forest, when all three of these beliefs are met, consider what resources the people will be used and be able to exploit, regardless of the level of damage they cause 
to the environment, such as the use of unforeseen timber, other harvesting of forest products such as honey, mushrooms, bamboo and others. Thus, the choice of plant species for the plantation is required by the villagers to participate in the "win-win situation". But if people are removed from the forest and considered the forest to be the only state, natural resources are more likely to be depleted without anyone involved in informing the authorities until they are properly allocated. From the emergence of the forest, which results in improved agricultural conditions of the farmers, the active protection and protection of the forests will give the villagers a return on the benefits and sustainability of the forests.

\section{Acknowledgement}

Without the academic support from lecturers from the National University of Laos and many people at the central, provincial and district level, this paper will be impossible. Thus, the authors would like to thank many people and staff especially the Champasak Provincial Office for Agriculture and Forestry, and anonymous reviewers of this paper.

\section{References}

1. Berkmüller, K., Southammakoth, S., \& Vongphet, V. 1995. Protected area system planning and management in Lao
PDR: status report to mid-1995. Lao-Swedish Forestry Cooperation Programme and IUCN. Vientiane.

2. Coulibaly-Lingani, P., Savadogo, P., Tigabu, M., \& Oden, P.C. 2011. Factors influencing people's participation in the forest management program in Burkina Faso, West Africa. Forest Policy and Economics, 13(4), 292-302. doi:https://doi.org/10.1016/j.forpol.2011.02.005

3. DOF. 2005. Forestry Strategies of Laos to year 2020 Department of Forestry. Vientiane, Laos.

4. DOF. 2007. Forestry sector development report for 2006 2007. Department of Forestry, Ministry of Agriculture and Forestry. Vientiane, Lao PDR.

5. DOF. 2015. Scaling Up Participatory Sustainable Forest Management (SUPSFM, alternative acronym: SUFORD-SU. Department of Forestry. Vientiane, Laos.

6. MAF. 2011. Forest Investment Program (FIP): Lao Investment Plan. Ministry of Agriculture and Forestry. Vientiane Capital.

7. Robichaud, W., Marsh, C. W., Southammakoth, S., \& Khounthikoummane, S. 2001. Review of the national protected area system in Lao PDR. Vientiane, Lao PDR: LaoSwedish Forestry Programme, Department of Forestry.

8. Sanonty, S. 2002. Forest policy reviews in Lao PDR. In T. Enters \& R. N. Leslie (Eds.), Forest policies and forest policies reviews (pp. 113). Bangkok, Thailand: EC-FAO partnership programme.

9. World Bank, SIDA, Ministry of Foreign Affairs, \& Governement of Finland. 2001. Lao PDR production forestry policy: status and issues for dialogue. (Vol. I). Vientiane, Laos: World Bank, Sida, Ministry of Foreign Affairs and Government of Finland.

10. Yin, R. K. 2009. Case Study Research: Design and Methods. SAGE Publications. $\quad$ Retrieved from https://books.google.la/books?id=FzawIAdilHkC 